\title{
A violência contra as mulheres e o movimento feminista dos anos 1970 nos EUA a partir de Nancy Fraser e Angela Davis
}

\author{
Violence against women and the 1970s feminist \\ movement in the USA based on Nancy Fraser and \\ Angela Davis
}

\section{Barbara Cristina Soares Santos ${ }^{\mathrm{a}}$}

Devemos lutar para unir nossos esforços a fim de garantir a segurança das mulheres com nossas preocupações a respeito da segurança deste planeta.

Angela Davis, 2017 [1984].

Resumo Analisando a luta do feminismo estadunidense dá década de 1970, Nancy Fraser $(1985 ; 1988 ; 1989)$ relata o processo pelo qual as ativistas determinaram a violência doméstica contra as mulheres como uma questão genuinamente política. Por meio de uma luta pela interpretação das necessidades das mulheres, elas romperam com o discurso individual que naturalizava essa violência. Por outro lado, Angela Davis (1981; 1984) também teceu uma densa análise sobre o mesmo movimento destacando que, embora fosse um ativismo necessário, que pretendia eliminar a violência contra as mulheres através de uma renovação do discurso público sobre essa violência, ele era insuficiente no seu princípio por desconsiderar a questão racial como fundamento desse tipo de violência, resultando num ativismo que ocluía mulheres não-brancas. Desse modo, a partir dos trabalhos de Fraser e Davis, intenta-se aqui realizar uma análise sobre essas mobilizações feministas, seus potenciais e suas limitações referentes às lutas das mulheres, tanto em seu aspecto político quanto epistemológico.

Palavras-chave feminismo. violência contra as mulheres. Nancy Fraser. Angela Davis. racismo.

a Doutoranda em Ciência Política,na área de Teoria Política, pela Universidade de São Paulo (USP), instituição pela qual também é mestra. Bolsista pelaCoordenação de Aperfeiçoamento de Pessoal de Nível Superior (CAPES). Integrante da GIRA, Grupo de estudos-intervenção antirracista e anticolonial. E-mail: barbara.cristina.santos@usp.br 
Abstract Analyzing the USA's feminism struggle in the 1970s, Nancy Fraser (1985; 1988; 1989) reports the process by which the activists determined domestic violence against women as a genuinely political issue. Through a struggle for the interpretation of women's needs, they broke with the individual discourse that naturalized this violence. On the other hand, Angela Davis $(1981 ; 1984)$ also conducted a careful analysis of the same movement. She highlights that, although the activism which aimed to eliminate the violence against women through a renewal of the public discourse about this issue was necessary, it was insufficient in its principle because it disregarded the racial issue as the foundation of this type of violence, which resulted in a type of activism that occluded non-white women. Thus, based on the works of Fraser and Davis, the aim is to carry out an analysis of these feminist mobilizations, the potentials and limitations of the women's struggles in their political and epistemological aspects.

Keywords feminism. violence against women. Nancy Fraser. Angela Davis. racism.

\section{INTRODUÇÃO}

Pensando a partir dos movimentos sociais de seu tempo, Nancy Fraser (1985; 1988; 2013 [1989]) propõe uma reconstrução de uma teoria crítica ${ }^{1}$ que estivesse preocupada com a prática feminista e atenta às dominações de gênero. Esse seu movimento teórico exigiu buscar formas concretas de alcançar a igualdade no acesso aos meios de interpretação e comunicação das necessidades de grupos subordinados, em especial as mulheres, diante do Estado e das instituições.

Trata-se, portanto, da possibilidade de distintos grupos sociais terem as mesmas condições de interagir socialmente e reivindicar suas necessidades em meios culturais, econômicos e políticos sem serem subordinados pelos critérios valorativos institucionalizados que estabelecem os padrões excludentes de reconhecimento e de redistribuição material. Essa fundamentação normativa de justiça, que leve em conta as diversas formas de subordinação social e que se forme a partir de arranjos sociais que possibilitem a todos os integrantes da sociedade se inter-relacionarem enquanto pares, Fraser denominou de paridade de partici-

1 Fraser argumenta que a teoria de Habermas defende ao menos uma dimensão da separação entre público e privado que as feministas criticam; ele preserva um arranjo institucional que é compreendido como uma das bases fundamentais da subordinação das mulheres na modernidade. As relações de dominação em Habermas partiam do antecedente de que o trabalho remunerado e o Estado estão apartados da criação dos filhos e do trabalho doméstico. Fraser defende assim que uma teoria de fato crítica da sociedade precisa se atentar às questões de subordinação de gênero para formar suas categorias de entendimento do capitalismo (Fraser, 2013). 
pação $o^{2}$. Assim, quando se pensa com a autora em um objetivo crucial da paridade de participação, vem logo em mente garantir independência e voz política em um canal institucional viável a todos.

Pode-se dizer que o debate sobre paridade em Fraser tem forte influência do contexto do Estado de bem-estar social referente à questão da necessidade, considerando as demandas estadunidenses sobre quem deveria suprir as necessidades da sociedade e quais seriam essas necessidades. Ou seja, é uma categoria política em disputa entre grupos sociais a respeito do que as pessoas precisam e quem irá definir isso, e torna-se, para Fraser, um meio de contestação e elaboração política, "um idioma no qual o conflito político é executado e as desigualdades são simbolicamente elaboradas e desafiadas" (Fraser, 2013, p. 53-54).

Considerando a noção de teoria crítica sensível às questões de gênero que Fraser defende, torna-se fundamental compreender qual a implicação das necessidades entre as esferas econômicas, política e doméstica da vida. A autora não propõe analisar as necessidades em si, mas os discursos sobre as necessidades, com o intuito de transformar a perspectiva política sobre elas; ou seja, o foco está em analisar a política de interpretação das necessidades. Nesse sentido, Fraser destaca o movimento feminista dos anos 1970 como um agente crucial na politização das necessidades das mulheres. Segundo ela, a luta das feministas estadunidenses contribuiu diretamente para reinterpretar o discurso da violência contra as mulheres. Ao ocuparem espaços da opinião pública, foi possível a elas determinar que a violência doméstica era uma questão política, e não unicamente uma violência individual e pessoal e, assim, contribuírem no desenvolvimento de políticas públicas e judiciárias para combatê-la.

Paralelamente, Angela Davis (2016 [1981]; 2017 [1984]) também desenvolveu uma interpretação sobre o mesmo movimento feminista; de acordo com a autora, este era um ativismo que trouxe contribuições significativas para o combate à violência contra a mulher principalmente por meio da criação de um novo discurso público sobre esse tipo de agressão. Mas, para além da transformação discursiva na esfera pública, o movimento desconsiderava na sua experiência a questão racial como fundamento desse tipo de violência.

De acordo com Davis, no pós-escravidão, um terço das mulheres negras foi destinado ao trabalho doméstico que, enquanto exploração racial e econômica, preservava resquícios escravocratas. Isso mostra que a violência doméstica dos

2 Para saber mais sobre o conceito de paridade de participação, ver: Fraser (2007, 2013, 2017); Bressiani (2007,2010, 2015); Melo (2018); Santos (2020). 
anos 1970 não era um fato novo, mas representava a continuidade histórica de uma violência de gênero e raça, junto aos demais tipos de violência no mundo do trabalho remunerado que mulheres negras já enfrentavam com a dupla jornada.

Sendo assim, ao mesmo tempo que o movimento era fundamental em promover um novo discurso na esfera pública que possibilitasse difundir socialmente que a violência contra a mulher era um problema de todos e que precisava ser impedido por meio de ações do Estado, essas mobilizações feministas, enquanto transformadoras dos discursos acerca da violência contra as mulheres tanto institucionalmente quanto na opinião pública, merecem alguns apontamentos sobre questões que pareciam estar ocluídas na sua luta, mas que originam essa violência: a sua racialização.

Diante desse cenário, busca-se nesse escrito, primeiramente investigar a análise de Fraser e de Davis sobre o movimento feminista dos anos 1970 nos EUA; e, a partir disso, promover uma articulação entre as duas leituras, apontando algumas lacunas presentes na argumentação de Fraser no que se refere a olhar para um movimento que, na realidade, pouco considerava o fator racial que atravessava essa violência, resultando em não atender as demandas de muitas mulheres afro-latinas que eram-são constantemente violentadas pelo racismo. Com isso, o intuito geral é propor uma leitura desse feminismo que seja atravessada pelo racial em seu fundamento, permitindo compreender não apenas seus potenciais, mas suas limitações, como tentativa de promover um espaço político e teórico que seja de fato mais aberto às questões raciais.

\section{NANCY FRASER E A POLITIZAÇÃO DAS NECESSIDADES DO MOVIMENTO FEMINISTA ESTADUNIDENSE DOS ANOS 1970}

Ao teorizar sobre a politização das necessidades, Fraser (2013) destaca a importância de analisar os processos nos quais determinados assuntos transitam de âmbitos de privacidade discursiva e com públicos específicos e fechados para serem contestados amplamente. Influenciada por Gramsci, Fraser denomina de grupos hegemônicos, dominados por homens de determinada cor e status socioeconômico, aqueles que possuem o poder de definir as questões políticas, que geralmente são postas em oposição àquilo que é econômico, doméstico ou pessoal; enquanto que mulheres formariam grupos contra-hegemônicos e contestariam o que é estabelecido como político, no sentido de politizar o que é desconsiderado pelos grupos dominantes. Quando as interpretações políticas, antecipadamente 
impostas por um público hegemônico, vão sendo questionadas, os blocos dominantes passariam a ser disputáveis.

A partir disso, a filósofa classifica dois tipos básicos de instituições que despolitizam necessidades sociais de grupos contra-hegemônicos: 1) as instituições domésticas, com destaque para a família nuclear moderna e patriarcal, que despolitiza determinados temas, ao pessoalizá-los por completo, colocando-os dentro do âmbito privado-doméstico ou pessoal-familiar e impossibilitando o debate público e político; 2) as instituições de ordem econômica, (locais de trabalho, mercados, empresas e corporações privadas) que despolitizam certas questões ao justificarem que elas pertencem ao mundo do mercado e, portanto, são impessoais, problemas técnicos que devem ser resolvidos por gestores e administradores.

Embora as instituições domésticas se diferenciem em vários pontos das instituições oficialmente econômicas, ambas fundamentam discursos de autoridade a partir de certas interpretações discursivas das necessidades que aparecem como naturais e, portanto, inquestionáveis, favorecendo determinados grupos dominantes. Esse movimento promove e sustenta relações de dominação e subordinação ao bloquear a contestação de questões políticas e impedir o conflito de interpretações dispersas nessas instituições. Fraser traz, como exemplo fundamental desse processo de dominação, a violência contra a mulher:

Se a violência doméstica, por exemplo, é fixada como um assunto 'pessoal' ou ‘doméstico’ dentro de famílias nucleares chefiadas por homens; e se o discurso público sobre esse fenômeno for canalizado para públicos especializados e associados, digamos, ao direito de família, ao trabalho social e à sociologia e psicologia do desvio, então isso serve para reproduzir a subordinação das mulheres aos homens (Fraser, 2013, p. 62-63, tradução própria).

Quando os discursos da interpretação das necessidades surgem enquanto um problema de idioma político, eles possibilitam uma porosidade maior nas fronteiras do que é econômico ou doméstico. As necessidades politizadas, portanto, são aquelas que romperam com os discursos dominantes em uma arena social, âmbito no qual as necessidades politicamente alternativas são traduzidas e disputadas no idioma do Estado para serem garantidas por ele. A partir dessa arena social, Fraser classifica a diversidade de falas sobre as necessidades em três categorias de discurso, de acordo com a forma como elas concorrem e se articulam: as formas opositoras, os discursos de reprivatização e os discursos de especialistas. 
As formas opositoras se configuram quando grupos subalternos, no caso feministas lutando contra a violência, opõe-se às identidades e aos papéis subordinados - determinados pelas interpretações dominantes das necessidades- e formam novas identidades sociais. Quando tais grupos falam publicamente sobre necessidades que foram despolitizadas para exigir que se tornem demandas com importância política legítima, eles realizam sérias ações e transformações políticas: 1) questionam as fronteiras demarcadas entre política, economia e doméstico; 2) promovem interpretações próprias e alternativas de suas necessidades; 3) essas interpretações alternativas são propagadas a partir da formação de novos e diferentes públicos de discurso; e 4) ao criarem distintas formas de discurso, alteram, desafiam e deslocam fronteiras hegemônicas dos meios de interpretação. Sobre a ação das feministas, como grupo com discurso opositor em relação à violência, Fraser argumenta:

na atual onda de fermentação feminista, grupos de mulheres politizaram e reinterpretaram várias necessidades, instituíram novos vocabulários e formas de tratamento e, assim, tornaram-se 'mulheres' em um sentido diferente, embora não incontestável ou unívoco. Falando publicamente o que antes era indescritível, cunhando termos como 'sexismo', 'assédio sexual', [... ]'estupro por alguém conhecido', 'segregação sexual na força de trabalho', 'dupla jornada', 'violência contra mulher' etc. ; mulheres feministas se tornaram 'mulheres' no sentido de uma coletividade política discursivamente auto-constituída, embora muito heterogênea e fragmentada (Fraser, 2013, p. 67, tradução própria).

As feministas estadunidenses realizaram uma reinterpretação discursiva sobre a experiência da violência e projetaram um novo agrupamento de necessidades ligadas a essa prática de dominação. Antes, como descreve Fraser, esse tipo de violência era considerado puramente pessoal, mas com o discurso feminista ele atravessa as diversas ordens de interpretação das necessidades (econômica, política e pessoal), politizando essas demandas. No mundo concreto, isso significa que para as mulheres se protegerem da estrutura machista, elas necessitam, para além do âmbito social do discurso, de políticas públicas que possibilitem empregos, acesso à educação, moradia e saúde.

Entre essas necessidades atendidas, estava a organização de abrigos para mulheres que foram agredidas e as formas de conscientização. Nesses locais, havia uma administração não hierárquica, não se diferenciando nitidamente quem era a equipe de apoio e quem eram as usuárias do projeto, podendo até mesmo esses 
papéis se inverterem e mulheres que foram agredidas também trabalharem como acolhedoras, ou seja, entre elas também iam se formando ações ativistas feministas. Isso fazia com que as mulheres agredidas fossem progressivamente mudando as próprias interpretações das violências sofridas e com isso suas identidades sociais: saiam de culpadas e defensoras dos agressores para vítimas e agentes, transformando suas autodescrições e negando a interpretação dominante em favor de uma leitura politizada, que lhes possibilitassem novas formas de agência, passando a se incorporarem ao reconhecimento de outras mulheres.

Vale notar, entretanto, que a politização das necessidades por discursos opositores não é inquestionável, e muitas vezes sofre uma disputa desigual. Isso pode ser visto por meio do segundo movimento de reação descrito por Fraser, os discursos de reprivatização, pelos quais grupos dominantes buscam reestabelecer as fronteiras que separam as ordens política, econômica e doméstica, ou seja, pretendem despolitizar esse processo a partir de vias institucionais, desmontando ou limitando os serviços de bem-estar social de modo discursivo. Um exemplo dessa despolitização são grupos conservadores e religiosos pró-vida que são contra o aborto por considerarem-no uma questão religiosa e não uma questão política envolvendo a vida das mulheres.

Já no terceiro modelo de discurso, o de especialistas, o foco primordial não é a politização contra a despolitização e sim o papel do conteúdo interpretado das necessidades. Aqui os principais adversários são os grupos organizados de oposição ou outras organizações que objetivam induzir e administrar a política pública, como empresas; assistência social; ONGs. Diferentes interpretações de uma mesma política pública competiriam entre si para delinear a interpretação hegemônica que poderia entrar para a agenda política formal; esses grupos especializados se tornariam concorrentes, embora ainda porosos, fazendo a mediação entre os movimentos sociais e o Estado.

Essa mediação dos discursos especializados teria uma base administrativa, pois se formariam a partir de procedimentos de tradução de necessidades politizadas em necessidades administráveis e burocráticas. Essa transição retrataria, por um lado, uma abstração das especificidades de raça, classe e gênero e de definições opositoras que se formaram no processo da politização dessa necessidade; por outro lado, se delineariam fundamentos que envolvem diretamente instituições específicas, como o trabalho assalariado, a formação das famílias (criação dos filhos, separação dos pais...) e o trabalho doméstico. Isso fez com que as pessoas, que demandavam essas necessidades, fossem realocadas ao longo desse processo, deixando de fazer parte de um movimento político para se tornarem 
casos individuais de necessidades; sem contar que se tornaram pessoas passivas, recebedoras de um serviço público pré-determinado, e não mais agentes ligados à interpretação de suas necessidades eà decisão sobre suas condições de vida. Devido a essa retórica administrativa e burocrática, os discursos das necessidades dos especialistas vão progressivamente se despolitizando. Ao se institucionalizarem nos aparatos do Estado, esses discursos voltam à normalização, reformando e até mesmo estigmatizando "desvios" de interpretação, além de barrar a possibilidade de os agentes construírem e desconstruírem os significados sociais.

Esse movimento de despolitização pode ser visto com relação aos abrigos de acolhimento de mulheres agredidas, que sofreram algumas transformações administrativas. Entre elas, estavam a separação demarcada entre profissional e usuária a partir da contratação de assistentes sociais, solapando a fluidez das relações presentes anteriormente, que eram fonte de conscientização e cuidado entre as mulheres atendidas. Esse tipo de administração foi despolitizando e individualizando as ações desses abrigos, fazendo com que as mulheres atendidas se colocassem como "clientes", além de serem cada vez mais psiquiatrizada se consideradas tão somente vítimas de ações individuais de violência. Disso resultou uma linguagem terapêutica que se sobrepunha à conscientização e ao atendimento científico de "abuso conjugal", o que, por sua vez, suplantou as conversas políticas sobre violência. Portanto, esse processo formou uma reinterpretação considerável das necessidades das mulheres que sofreram violência, passando-se de reivindicações sociais e econômicas com o objetivo de promover a independência dessas sujeitas para a centralização em demandas individuais, isto é, enquanto questões apenas psicológicas. Ou seja, as políticas de interpretação das necessidades se tornaram um gerenciamento de satisfação das necessidades.

Apesar dessa despolitização, Fraser propõe um mapeamento da luta que é contrária à administração das necessidades e em favor de sua resistência, o que permite um latente retorno à política. Isso pode ser visto com mais nitidez a partir de sua análise do movimento feminista de sua época. Aqui foi possível notar, além de algumas insuficiências na disputa discursiva pelas necessidades, o processo de transição de uma política de interpretação das necessidades para a administração da satisfação das necessidades. Mas também foi possível compreender, a partir das ações feministas, o movimento contrário, que vai da administração à resistência e, progressivamente, à política, ou seja, a transição de um movimento das necessidades individuais, culturais e informais para algo coletivo, político e formalmente organizado. 


\section{PENSANDO A RACIALIDADE DO MOVIMENTO FEMINISTA ESTADUNIDENSE COM ANGELA DAVIS}

Segundo Davis (2016; 2017), a despeito de o movimento da década de 1970 ser necessário e urgente, tendo como bandeira prioritária eliminar a violência contra as mulheres a partir de uma nova formação do discurso público sobre essa violência, ele era insuficiente na sua origem e, talvez, a reinterpretação das necessidades apontadas por Fraser, bem como a formação de novos públicos, só teve um resultado positivo e foi institucionalizada devido a um recorte racial de quem estava compondo o movimento feminista daquele período. Nesse sentido, pode-se questionar se a própria disputa pela interpretação das necessidades está limitada a um eixo definido de grupos; inclusive de grupos progressistas, mas que são menos marginalizados socialmente.

É possível criar um diálogo entre Fraser e Davis quando esta também narra que o movimento feminista antiestupro foi se consolidando a partir dos anos $1970^{3}$, período em que se notabilizou por conseguir maior visibilidade e apoio público. Entre os grupos que o compunham estava o das Feministas Radicais de Nova York, que realizou, pela primeira vez na história dos EUA, um fórum reunindo muitas mulheres para narrarem publicamente as violências sofridas; e o Mulheres da Região da Baía de São Francisco contra o Estupro, que, fundado por mulheres de Berkeley, promovia um serviço comunitário que possibilitava o atendimento, emergencial e 24 horas, de vítimas de agressões, influenciando a formação de outros abrigos e centros emergenciais que se dispersaram pelo país.

Ademais, Davis destaca que o movimento foi salutar em enfraquecer publicamente alguns mitos referentes à cultura do estupro, entre eles: a noção de que a vítima é moralmente culpada pelo crime sofrido; a ideia de que se a mulher não resiste à violência, é porque estava consentindo a violação do seu corpo; a suposição de que o estupro seria uma prática rara que aconteceria somente em lugares desertos com um estranho; e a ideia de que se tratava de uma necessidade biológica que os homens não conseguiam controlar. A verdade é que o estupro acontece repetidamente ${ }^{4}$, em qualquer lugar, com mulheres de todas as raças, etnias, idades,

3 Lembrando que foi no ano de 1971 que Angela Davis (2019) foi presa e tratada como uma terrorista muito perigosa. Nesse período, Davis já lutava diretamente contra a violência racista policial enquanto membra do Panteras Negras.

4 De acordo com a Rede Nacional de Assistência a Vítimas de Estupro, Abuso e Incesto, atualmente, a cada 68 segundos uma mulher é abusada sexualmente nos EUA, sendo 463. 634 casos de estupro ou outro tipo de assédio por ano (entre vítimas a partir dos 12 anos de idade). Para fazer um paralelo com o Brasil, segundo o $13^{\circ}$ Anuário de Segurança Pública (2019), o país registrou 66 mil casos de violência sexual em 2018, o que representaria 180 estupros por dia. 
classes e orientações sexuais, e está longe de ser predominantemente um impulso sexual incontrolável; antes disso, ele é um instrumento de poder utilizado para controlar e explorar as mulheres, sendo uma violência normatizada pela mídia e pelos padrões sociais do patriarcado.

Davis localiza o estupro como uma arma de tortura historicamente usada em mulheres escravizadas e em prisioneiras políticas; a KuKluxKlan, por exemplo, valia-se do estupro como uma forma de terror político. Olhar o estupro como um instrumento de poder permite situá-lo no contexto socioeconômico de forma estrutural e, assim, entender a natureza desse tipo de violência para finalmente ser possível combatê-lo, no lugar de oferecer apenas alternativas que tendem a servir para determinados grupos de mulheres cujas necessidades podem ser interpretadas:

O estupro tem relação direta com todas as estruturas de poder existentes em determinada sociedade. Essa relação não é simples, mecânica, mas envolve construções complexas que refletem a interligação da opressão de raça, gênero e classe característica da sociedade. Se nós não compreendermos a natureza da violência sexual como sendo mediada pela violência e poder raciais, classistas e governamentais, não poderemos ter esperança de desenvolver estratégias que nos permitam um dia purgar nossa sociedade da violência opressiva misógina (Davis, 2017, p. 49).

Sendo assim, mesmo todos aqueles mitos sendo desvendados e apontados criticamente por meio da ação concreta das feministas, havia um que foi desconsiderado pelo movimento dos anos 1970 e que é destacado por Davis como o mais traiçoeiro: aquele referente à suposição de que o estuprador é, a priori, um homem negro, o que mostra quem de fato estava se mobilizando entre as ativistas.

O mito do estuprador negro dos EUA nasce, segundo Davis, no fim do século XIX para justificar os linchamentos de negros após a Guerra Civil. Considerando que formas declaradas de escravidão não eram mais legais, os linchamentos apareciam como uma verdadeira arma política contra a comunidade negra do país, mas que precisava ter uma explicação mais convincente. Foi desse modo que a imputação do estupro aos homens negros surgiu como uma invenção política para afirmar os linchamentos: "Essa acusação mais chocante e explosiva, claro, era o estupro. Os linchamentos agora eram explicados e racionalizados como um método para vingar as agressões de homens negros contra a feminilidade branca do Sul” (Davis, 2016, p. 190). 
A propagação do mito do estuprador negro causou uma ruptura entre negros e brancos nos movimentos progressistas da época, fazendo com que brancos que antes lutavam pela libertação do povo negro se afastassem desse movimento. É possível articular essa ruptura com os movimentos feministas posteriores, já que essa separação racial parece se manter, atingindo diretamente a formação política e teórica das demandas e contribuindo para a manutenção do racismo dentro de vertentes do próprio movimento:

o mito do estuprador negro faz com que as pessoas desconheçam as realidades do estupro e o fato de que, por exemplo, mais de 90\% de todos os estupros são intrarraciais, e não inter-raciais. Mais do que isso, como foi indicado em estudos sobre agressão sexual - e, de fato, como acontecia na época da escravidão -, proporcionalmente mais homens brancos estupram mulheres negras do que homens negros estupram mulheres brancas. Ainda assim a mulher branca típica deste país [EUA] carrega uma suspeita muito maior dos homens negros do que dos homens brancos como potenciais estupradores (Davis, 2017, p. 46).

As mulheres brancas estadunidenses eram socializadas e educadas para terem mais medo de ser violentadas por um homem negro do que por um branco, muito embora os brancos compusessem a maior parte da população e refletissem estruturalmente o histórico escravocrata de abuso sexual de escravizadas. Isso, é crucial dizer, não significa que homens negros não possam ser violentos; Davis não quer substituir um mito por outro, inocentando homens negros que tenham cometidos crimes sexuais ou naturalizando uma falsa ideia de bondade do homem negro, muito pelo contrário. A autora está exigindo uma leitura complexa da realidade, que não ligue diretamente a violência contra a mulher a um fator racial essencialista, pois quando o movimento não desconstrói a ideia de que o estupro é sempre realizado por negros, ele colabora com uma prática social distorcida, que é racializada em seu fundamento, já que brancos também estupram, mas tendem a não ser denunciados ou responsabilizados.

Esse apagamento racial resultou em uma significativa barreira histórica para que o feminismo daquele período avançasse em vitórias que fossem comuns a todas, como a própria luta contra a violência. Isso marginalizou principalmente a luta de mulheres afro-americanas pelo fim estrutural da violência contra as mulheres e centralizou uma necessidade específica de uma vertente do movimento feministaque era eminentemente branco, de classe média - referente à violência doméstica 
e à manutenção da narrativa de que homens negros são mais perigosos do que os brancos, contribuindo para a violência policial contra a população negra.

Quando Fraser aponta que a violência contra as mulheres estava no campo doméstico e pessoal, e que foi o movimento feminista daquele período que deslocou por meio da luta essa dominação para o âmbito político, parece haver uma redução da violência doméstica a um espaço e sujeitos específicos, o que pode ofuscar a histórica violência vivida por mulheres negras via escravidão um século antes de 1970 nos EUA, e que se manteve posteriormente com novas especificidades. Segundo Davis, no pós-colônia, 30,8\% das mulheres negras foram fadadas ao trabalho doméstico em casa de famílias brancas, reproduzindo de forma mais refinada, agora com baixos salários e alforria, a exploração material e racial que a colonização criou.

Enquanto mulheres negras trabalhavam como cozinheiras, babás, camareiras e domésticas de todo tipo, as mulheres do Sul rejeitavam unanimemente trabalhos dessa natureza. Nas outras regiões, as brancas que trabalhavam como domésticas eram geralmente imigrantes europeias que como suas irmãs ex-escravas, eram obrigadas a aceitar qualquer emprego que conseguissem encontrar (Davis, 2016, p. 99).

Relacionar o trabalho doméstico como uma função naturalizada de mulheres negras é, até hoje, uma marca viva do processo colonial. Dessa forma, a violência doméstica não seria um fenômeno novo dos anos 1970, mas uma continuidade do colonial na pós-colonização. Por isso, referir-se apenas como uma violência localizada dá década de 1970 parece também limitar-se a uma violência própria das mulheres brancas.

O racismo presente no movimento de mulheres antiestupro tornou-se, assim, um dos maiores impeditivos desse feminismo conseguir conquistas que realmente promovessem o fim da cultura do estupro. Davis argumenta que um dos fatores que impossibilitou esse movimento de ser multirracial na prática, e, desse modo, atingir mais mulheres, foi a interferência que o mito do estuprador negro exercia entre as mulheres brancas.

Se investigarmos as razões pelas quais tem sido tão árduo assentar as bases para um movimento antiestupro multirracial efetivo descobriremos que a influência abominável do mito do estuprador negro se impõe. Durante os primeiros anos da década de 1970, quando a campanha antiestupro ainda estava em seu início, a 
presença de mulheres afro-americanas naquele movimento era raridade (Davis, 2017, p. 46, grifos meus).

Davis atrela parte dessa ausência de mulheres negras nas mobilizações à "consciência incipiente das mulheres brancas que foram pioneiras do movimento de libertação feminina a respeito da inter-relação entre racismo e sexismo em geral" (Davis, 2017, p. 46), estando ausente no movimento a noção de que a base dessa violência envolvia não só gênero, mas outros marcadores cruciais que, articulados, formavam violências específicas, como bem nos lembra Patricia Hill Collins:

Atos específicos de violência sexual contra afro-americanos refletem um processo mais amplo pelo qual a violência é socialmente construída de maneira especificamente racializada e generificada. Assim, mulheres negras, homens negros e mulheres brancas experimentam formas distintas de violência sexual (Collins, 2019, p. 252, grifos meus).

Como descreveu Fraser, historicamente, as mulheres agredidas não eram reconhecidas como vítimas de violência nem pela sociedade nem pelo sistema judicial, por isso um inconformismo diante de tamanha injustiça era transmitido diretamente aos homens por meio do ativismo. Conforme este foi se fundamentando por um alicerce teórico de feministas da academia, brancas e de classe média, as primeiras análises dessas autoras envolviam um caráter biológico e essencialista, e pouco social, para explicar a violência dos homens contra as mulheres, não abarcando o caráter racial e de classe para explicar os estupros e outras violências, o que mostra que a própria fundamentação epistemológica do movimento desse período era insuficiente para entender a exploração e a opressão de mulheres não-brancas da classe trabalhadora, além de essas teorias também contribuírem para o mito biologizante do homem negro como um agressor em potencial. Nesse sentido, pode-se questionar se o motivo pelo qual as instituições oficiais do Estado deram uma abertura mínima para ouvir a interpretação contra-hegemônica das necessidades das feministas seria justamente por não ser uma ação tão radical, que considerasse como ponto central nesse discurso o combate ao racismo.

As ativistas feministas brancas não enxergavam o quanto o sexismo estava atrelado ao racismo para formar a dominação estrutural contra as mulheres. Elas tinham, talvez, como aponta Grada Kilomba (2019) o privilégio de não saber ${ }^{5}$,

5 Kilomba dissertajustamente sobre experiências cotidianas de racismo, onde a possibilidade de não se dar conta dessas experiências é um privilégio de não saber: "Uma vez confrontado com verdades 
defendiam o mito do estuprador negro, mas tampouco percebiam que isso era um problema fundante para se pensar feminismos emancipadores. Essa cegueira à raça fazia com que essas feministas, na disputa para que a sua interpretação da necessidade de não ser mais violentada fosse reconhecida, reafirmassem ao mesmo tempo, por meio do silenciamento ou da acusação enganosa, a ligação do estupro a homens negros. Essa incapacidade do movimento de desenvolver uma interpretação das necessidades que reconhecesse o nível estrutural que impulsionava a violência sexual articulado com o genocídio da população negra fez muitas mulheres não-brancas declinarem de se envolver pessoalmente com as mobilizações:

Como grande parte do ativismo inicial contra o estupro se concentrava em colocar os estupradores nas mãos do sistema judicial, as mulheres afro-americanas relutavam, compreensivelmente, em se envolver com um movimento que poderia muito bem levar a mais ataques repressivos às suas famílias e comunidades (Davis, 2017, p. 46, grifos meus).

Geralmente, as ações policiais para apreender agressores sexuais eram acompanhadas de um armamento racista de repressão: 1) o suspeito é descrito de forma genérica, permitindo a violência policial seguida de morte de muitos homens negros inocentes até chegar ao suposto realizador do crime; 2) aumento considerável do arsenal policial (aeronaves, cães farejadores, agentes policiais, helicópteros) para a busca, o que posteriormente se mantém como lógica normatizada da ação policial para outras situações; e 3) a atenção policial ser dada normalmente quando a vítima é uma mulher branca, enquanto as mulheres negras eram consideradas promíscuas (Davis, 2016; Collins, 2019). Por apoiar esse tipo de agenda policial para combater a violência contra a mulher, já que uma das bandeiras do movimento era jogar os estupradores no sistema judicial, parte das feministas daquele período acabou por contribuir indiretamente com o terror policial em comunidades negras, favorecendo seu genocídio.

Enquanto muitos agressores brancos não são devidamente julgados pelos tribunais, o mesmo não ocorre quando o foco do estupro são homens negros, que em sua maioria são julgados e culpados, ou até mesmo culpados sem julgamento.

desconfortáveis desta história muito suja, o sujeito branco comumente argumenta: 'não saber..., 'não entender..., 'não se lembrar...', 'não acreditar...' ou 'não estar convencido por...' Estas são expressões desse processo de repressão, no qual o sujeito resiste tornando consciente a informação inconsciente, ou seja, alguém quer fazer o conhecido, desconhecido" (Kilomba, 2019, p. 42). 
Por isso, Davis sustenta que a falsa acusação do estupro é um recurso do racismo, que era naturalizada e empregada com frequência para legitimar a violência e a brutalidade da polícia contra a população negra, ou seja, a busca pelo auxílio da polícia e justiça diante da violência contra a mulher tem um recorte fundante de raça e classe. Mulheres negras e pobres não possuem o direito de confiar nessas instituições porque elas, quando agredidas, receiam a própria atuação dos policiais e juízes - já que é recorrente o assédio de policiais a mulheres negras - além de temerem por seus familiares, que tendem a ser os principais suspeitos de crimes não cometidos devido ao racismo: "A violência contra as mulheres negras tende a ser legitimada e, portanto, perdoada, enquanto a mesma violência em outros grupos pode ser não legitimada e não desculpável. Ao longo da história, essa violência conquistou o apoio e o controle do Estado" (Collins, 2019, p. 251).

Por tudo isso, Davis reforça que o movimento feminista tem o dever de estar atento a essas complexidades se almeja a emancipação total das mulheres, para além de olhar apenas para as formas institucionais de atendimento às vítimas, como os abrigos emergenciais exemplificados por Fraser, que são essenciais por lidarem pontualmente com os resultados dessas violências, mas insuficientes para enxergar o seu fundamento racializado e que permite sua propagação. Davis também nos convida a olhar para nosso presente quando estabelece uma relação entre a violência contra a mulher e a violência neocolonialista contra povos africanos e ameríndios, manifestando que a raiz da agressão contra mulheres só será eliminada se tal violência for compreendida dentro de um contexto sociopolítico estrutural assolado pelo imperialismo:

Exatamente as mesmas condições sociais que geram a violência racista - que encorajam os ataques a trabalhadoras e trabalhadores e a postura política que justifica a intervenção dos Estados Unidos na América Central e o auxílio ao governo do apartheid na África do Sul - incitam a violência sexual. Por conseguinte, a violência sexual nunca será completamente erradicada enquanto não levarmos a cabo com sucesso uma gama completa de transformações sociais radicais em nosso país (Davis, 2017, p. 50-51).

Por fim, a autora também faz um processo de rememoração da luta, que é constantemente apagada, ao lembrar que o movimento dos anos 1970 não foi o primeiro a lutar pelo fim da violência contra as mulheres nos EUA, mas sim o 
Movimento Associativo de Mulheres Negras ${ }^{6}$, fundado na década de 1890. É salutar destacar a importância, um século antes, que essas mulheres negras davam à luta contra a violência, refletindo oitenta anos de um organizado combate do estupro e da ameaça sexual. No presente, é possível notar que a ideia formada na escravidão de que as mulheres negras eram propriedade dos senhores brancos é uma violência simbólica e material que permanece na contemporaneidade, quando as vidas dessas mulheres são reificadas e apagadas.

\begin{abstract}
É ainda mais contraditório que as mulheres negras tenham estado ausentes no início do movimento antiestupro contemporâneo, já que, na verdade, o ativismo antiestupro tem uma longa história na comunidade negra. É provável que o primeiro movimento progressista a incitar uma contestação direta à violência sexual tenha sido o Movimento Associativo de Mulheres Negras, formado no fim dos anos 1890 (Davis, 2017, p. 47).
\end{abstract}

Por tudo isso, seria bastante limitador reduzir o estupro e outras agressões a casos individuais ou a fatores biológicos e psicológicos. Fraser vai diretamente contra essa ideia, principalmente quando apresenta todo o movimento de politização dos discursos e das demandas feministas para uma ordem não só pessoal, mas também social, sendo crítico à falta de política pública do Estado em relação à violência contra as mulheres, e conseguindo promover essas políticas. Por outro lado, o movimento ativista dos anos 1970 possuía limitações concretas à emancipação das mulheres por não conseguir reinterpretar suas necessidades de forma ampla e plural como parecia, principalmente por não considerar o fundamento racial que essa violência abarcava.

\title{
CONSIDERAÇÕES FINAIS
}

Na análise de Fraser, as feministas que conseguiram disputar discursivamente e reinterpretar as necessidades referentes ao combate à violência contra as mulheres formavam um grupo específico, que, demonstrou Davis, não contemplava

6 As lideranças do Movimento Associativo não vinham das camadas baixas da classe trabalhadora, mas eram mulheres negras intelectualizadas. Entretanto, o que as diferenciava das feministas líderes das agremiações brancas "era sua consciência sobre a necessidade de contestar o racismo" (Davis, 2016, p. 135, grifos meus), que lhes era cotidiano. Assim, a experiência do racismo sofrido diariamente fazia com que as líderes negras se aproximassem mais das mulheres trabalhadoras, brancas e negras, do que da experiência do sexismo vivenciado pelas mulheres brancas de classe média. 
mulheres afro-americanas, latinas e indígenas, já que sua maioria era representada por mulheres brancas, intelectualizadas de classe média, que eram também subordinadas socialmente pelo machismo, mas tinham mais possibilidade de disputar discursivamente suas demandas individuais no Estado.

Não obstante a considerável formação de um discurso próprio e auto gerado, a partir desse feminismo, que permitiu ampliar a noção de político e garantir um espaço legítimo na esfera pública às mulheres, além de também contribuir fortemente ao combate à cultura do estupro, fazendo coro com Davis, Collins nos atenta que havia uma questão anterior ainda pouco resolvida, referente a quem tinha voz para participar e gerar ativamente esses discursos emancipadores. Devido à violência colonial, muitas mulheres negras não possuíam o direito à voz há muito tempo, já que se expor publicamente oferecia risco a suas vidas e à vida de seus entes. Esse pode ser um dos motivos históricos pelos quais os discursos sobre a interpretação das necessidades foram desenvolvidos por mulheres brancas, e o movimento ser pouco formado por mulheres negras:

Em um contexto de racismo virulento [início do séc. XX], a exposição pública poderia tornar homens e mulheres negros mais vulneráveis ao risco de violência sexual cometida por homens brancos. As mulheres brancas que desenvolvem análises orientadas pela questão do gênero não enfrentaram esse medo. Em situações como essas, nas quais a regulação dos corpos das mulheres negras beneficiava os sistemas de raça, classe e gênero, a manutenção dos espaços seguros para a autodefinição das mulheres negras muitas vezes exigia que, em público, se mantivesse silêncio sobre questões aparentemente polêmicas (Collins, 2019, p. 219-220).

Por outro lado, esse movimento feminista aparece em Fraser como bastante transformativo da ordem vigente, por ter inserido na opinião pública a interpretação de que a violência contra a mulher é um problema social, político e sistêmico, além de ter conseguido também implementar políticas públicas que pudessem atender e acolher as vítimas. Collins, todavia, mostra que até mesmo essas conquistas eram direcionadas a um grupo específico, pois eram poucas as mulheres negras que conseguiam acessar essas políticas públicas:

Embora as estatísticas atuais indiquem que as mulheres negras têm mais probabilidade de sofrer estupro que as mulheres brancas, elas são menos propensas a conseguir que julgamentos resultem em condenações de seus algozes e, o que é 
ainda mais perturbador, menos propensas a procurar aconselhamento e outros serviços de apoio (Collins, 2019, p. 253).

Ademais, Davis argumenta que a diferenciação sexista entre economia doméstica como feminino e economia pública como masculino causada pelo capitalismo industrial, pós-Guerra Civil norte-americana, fortaleceu ainda mais a imagem de inferioridade e fragilidade apenas das mulheres brancas, a partir de uma ideologia da feminilidade, fazendo com que elas fossem separadas do mundo do trabalho produtivo remunerado e vistas como a "mãe" e a "dona de casa". No entanto, entre mulheres negras escravizadas, esse movimento nunca ocorreu: "os arranjos econômicos da escravidão contradiziam os papéis sexuais hierárquicos incorporados na nova ideologia. Em consequência disso as relações homem-mulher no interior da comunidade escrava não podiam corresponder aos padrões da ideologia dominante" (Davis, 2016, p. 24-25). Isso mostra o quanto o caráter patriarcal é racializado por uma estrutura social embranquecida. Desse modo, o que pode se considerar é que o movimento antiestupro, justamente por ter sido encabeçado por mulheres brancas, estadunidenses, de classe média, permitiu dar mais visibilidade ao Estado e à opinião pública de uma violência que outras mulheres já sofriam um século antes.

Diante desse cenário, portanto, pode-se concluir que processo de despolitização das necessidades desenvolvido por Fraser, pode ser mais complexo do que aparenta. A autora aponta que esse processo acontece quando os arranjos institucionais e administrativos tornam a interpretação das necessidades um gerenciamento de necessidades, fazendo os sujeitos não serem mais autores críticos dos discursos, apenas clientes individualizados de uma política pública. Mas o que se nota é que, para além dessa despolitização governamental, as próprias interpretações progressistas em disputa no âmbito público podem antes já despolitizar outras interpretações marginalizadas. No estudo de Davis sobre o mesmo movimento, pode-se perceber que este não foi tão transformativo porque a interpretação das feministas brancas, antes de ser despolitizada pelo Estado, já apagava outras interpretações sobre o mesmo assunto, entre concernidas. Talvez em Fraser esse movimento dos anos 1970 apareça de forma mais central do que ele atuou para combater a violência contra as mulheres nos EUA, não havendo uma articulação com outras formas de disputa emancipatória por interpretação dessa necessidade, abrindo margem para categorizá-lo como o movimento feminista central do período: 
Essa organização acabou impactando públicos mais amplos e discursivos. No final dos anos 1970, as feministas conseguiram em grande parte estabelecer a violência doméstica contra as mulheres como uma questão política de boa-fé. Em alguns casos, elas conseguiram mudar atitudes e políticas da polícia e dos tribunais e conquistaram para esse assunto um lugar na agenda política informal. Agora, as necessidades das mulheres agredidas eram suficientemente politizadas para se tornarem candidatas à satisfação organizada publicamente. Finalmente, em vários municípios e localidades, os abrigos de movimento começaram a receber financiamento do governo local (Fraser, 2013, p. 73, grifos meus, tradução própria).

Davis também mostrou que esse tipo de violência deriva diretamente da política oficial, ou seja, da política hegemônica do Estado. Quando uma reinterpretação das necessidades é incluída, ela tende a ser despolitizada, como definiu Fraser. Desse modo, o sistema de dominação se mantém firme, já que apenas setores já privilegiados em algum aspecto (como é o caso das feministas brancas) conseguem entrar na disputa enquanto interpretações ditas contra-hegêmonicas. Nesse sentido, diferente do que parece apontar Fraser, as políticas da polícia e dos tribunais mantiveram a atitude histórica de penalização de mulheres negras, continuando a contribuir para a violência sistêmica contra elas:

A experiência dos anos 1970 demonstra que as estratégias antiestupro que dependem, sobretudo, das agências de aplicação da lei continuarão a deixar de lado muitas mulheres de minorias étnicas. Na verdade, a vivência das mulheres negras tem sido a de que exatamente os mesmos policiais brancos encarregados de protegê-las dos estupradores e de outros criminosos às vezes irão tão longe ao ponto de estuprar as mulheres negras sob sua custódia. [...] Além disso, as forças policiais com frequência empregam táticas aparentemente elaboradas para capturar os estupradores, mas que tem como objetivo velado expandir seu arsenal de repressão racista (Davis, 2017, p. 49-50).

Me pergunto assim quais seriam as limitações da paridade de participação referentes às pessoas negras nas esferas institucionais, públicas e íntimas da vida. A partir da leitura de Davis, pode-se alegar que talvez a política de interpretação das necessidades do movimento feminista tenha sido insuficiente por apenas promover a justiça para determinados grupos, mesmo sendo grupos subordinados, enquanto outros seguiriam marginalizados até para participar de forma 
paritária na interpretação de discursos, enquanto essa paridade já seria possível para algumas mulheres.

A violência contra as mulheres, portanto, é racial. E, como alega Davis, envolve toda uma rede de brutalidade que se prolonga a métodos terroristas de grupos religiosos "pró-vida" ao atacarem clínicas e hospitais de atendimento de mulheres que foram intimidadas, agredidas e estupradas; às próprias ações criminosas do governo quando não subsidia o aborto, os métodos contraceptivos e a educação sexual; além do machismo cotidiano que faz do estupro uma cultura enraizada nas corporalidades e mentalidades, e que se estende à não garantia dos direitos reprodutivos pelo Estado, atingindo principalmente as mulheres negras e pobres que precisam desses serviços, comprovando os intercruzamentos que essa violência possui com violações à humanidade dos corpos racializados.

Por isso, levar o debate racial como foco central dentro dos feminismos é um movimento urgente que muitas mulheres não-brancas reivindicam cotidianamente a partir da particularidade das violências que sofrem, mas também a partir das potencialidades que desenvolvem ao resistirem e existirem. Pensar teorias e ações conjuntas envolve, portanto, um compartilhamento de escuta e de fala que possibilite considerar as diferentes experiências e não esquecer as lutas já vivenciadas.

\section{REFERÊNCIAS BIBLIOGRÁFICAS}

BRESSIANI, Nathalie. (2007). "Multiculturalismo ou Desconstrução? Reconhecimento em Young e Fraser". In.: Humanidades em diálogo, v.1, n. 1, nov.

BRESSIANI, Nathalie. (2010). Economia, Cultura e Normatividade O debate de Nancy Fraser e Axel Honneth sobre redistribuição e reconhecimento. Dissertação de mestrado em Filosofia, Universidade de São Paulo.

BRESSIANI, Nathalie. (2015). Crítica e Poder. Democracia Deliberativa e Diagnóstico de Patologias Sociais em Nancy Fraser. Tese de doutorado em Filosofia, Universidade de São Paulo.

COLLINS, Patricia Hill (2019). Pensamento feminista negro: conhecimento, consciência e a política do empoderamento. São Paulo: Boitempo.

DAVIS, Angela. Mulheres, cultura e política (2017 [1984]). São Paulo: Boitempo.

DAVIS, Angela (2016 [1981]). Mulheres, raça e classe. São Paulo: Boitempo.

DAVIS, Angela (2019). Uma autobiografia. São Paulo: Boitempo.

FÓRUM DE SEGURANÇA PÚBLICA (2019). $13^{\circ}$ Anuário de Segurança Pública. https:// www.forumseguranca.org.br/wp-content/uploads/2019/o9/Anuario-2019-FINAL-v3. pdf (acesso em 20/01/2020). 
FRASER, Nancy (2013). Fortunes of Feminism. London/New York: Verso.

FRASER, Nancy; Nicholson, Linda (1988).Social Criticism without Philosophy: An Encounter between Feminism and Postmodernism. Theory Culture and Society, v. 5 .

FRASER, Nancy. (2007). "Mapeando a imaginação feminista: Da redistribuição ao reconhecimento e à representação”. Estudos feministas, 15 .

FRASER, Nancy. (2017). "Heterossexismo, falso reconhecimento e capitalismo: uma resposta a Judith Butler”. In.: Idéias, Campinas, v.8, n.1, p. 277-294, jan/jun.

FRASER, Nancy (1989). Unruly practices. Power, discourse and gender in contemporary social theory. Minneapolis: University of Minnesota Press.

FRASER, Nancy. (1985).What's Critical about Critical Theory? The Case of Habermas and Gender. New German Critique, n. 35, p. 97-131.

KILOMBA, Grada (2019). Memórias da Plantação: Episódios de racismo cotidiano. Rio de Janeiro: Cobogá.

MELO, Rúrion. (2018) "Dimensões políticas do reconhecimento e seus limites". Dissonância: Revista de Teoria Crítica, v. 2, p. 112-148.

RAPE, Abuse, \& Incest National Network (RAINN). Victims of Sexual Violence: Statistics. https://www.rainn.org/statistics/victims-sexual-violence (acesso em 20/08/2021).

SANTOS, Barbara. (2020). Paridade de participação e emancipação em Nancy Fraser: reconhecimento e justiça a partir do feminismo. Dissertação de mestrado em Ciência Política, Universidade de São Paulo.

Recebido: 20/05/2021 | Aprovado: 15/08/2021 